\title{
Literary English and the Challenge of Multimodality
}

\author{
Catherine Beavis* \\ AQ1 Faculty of Education, Griffith University, Australia \\ How to understand and argue for the nature and place of literary texts and \\ experience in contemporary English curriculum has been and continues to be \\ the subject of much debate. While literature as traditionally conceptualised \\ remains an important presence in much English curriculum, the notion of what \\ 'literature' is, or what the category of 'literary' texts and cultural forms might \\ encompass, in a context where literacy is understood as multimodal and English \\ and literacy curriculum addresses multimodal literacies accordingly, is less clear. \\ This paper addresses two areas with respect to literature and literature teaching \\ in the digital age: first, issues surrounding the ways in which national curricu- \\ lum guidelines in England and Australia envisage the teaching of literature, in \\ principle and in practice; and second, the challenges presented to print-based \\ conceptions of literature and literature teaching within English by significantly \\ broader conceptualisations of literature encompassing a range of aesthetic multi- \\ modal texts and forms. The kinds of insights, experience and understandings \\ generated through the study and creation of literary and aesthetic texts in \\ English, it is argued, are now needed more than ever. However, as literary expe- \\ rience becomes increasingly transmodal, how English seeks to manage media \\ shift to encompass both print and digital forms remains a challenging issue.
}

Keywords: literature; multimodality; aesthetic texts; curriculum

\section{Literature and national curriculum}

In a recent paper on the state of literature teaching in England, Goodwyn (2012) describes teachers' frustrations with the disparity between what they believed the experience of reading and teaching literature should be - 'essentially experiential, aesthetic and affective' and 'an authentic experience for the student with some genuine personal significance' (Goodwyn 2012, 213) - and actual classroom practice. These disparities were linked chiefly to centralised assessment demands, and with related textual choice and teaching practices tied to mandated curriculum and assessment requirements in the English National Curriculum. Underlying reduced opportunities for creative and personal responses, and for deep and extended engagement with complex texts, Goodwyn $(2012,213)$ observed, was a struggle whereby 'the rhetorical status of literary study is in tension with the real importance of literary engagement', and the 'true status' of literature 'has diminished' (Goodwyn, 2012, 224). In particular he noted that opportunity for 'the more creative and personal responses to literature that teachers especially value have been drastically diminished' and 'the kind of depth that teachers feel can be

*Email: c.beavis@griffith.edu.au 
gained from a thorough engagement with a longer and more complex text are almost impossible to manage[,] given "the imperative to secure progression" (Goodwyn 2012, 224). There seems little role for personal experience and engagement, yet 'empirical studies of literary reading ... are very clear that the personal is central to meaning making at all levels of engagement with a literary text' 10 (Goodwyn 2012, 224).

Against this backdrop, by contrast, Goodwyn (2012, 224) suggests that the Australian Curriculum: English 'appears to offer one example of a more progressive approach which recognizes the aesthetic nature of literary experience'. In this Curriculum, part of the incoming national curriculum in Australia, English for years $\mathrm{F}-10$ is organised into three strands: Language, Literacy, and Literature. This move accords a significant role to literature throughout the years of schooling, and across all States and Territories; in some instances, formalising what already exists and, in others, creating new emphases or priorities, or a version of 'English' that has not been seen for a number years.

20 The Literature strand 'aims to engage students in the study of literary texts of personal, cultural, social and aesthetic value [including] ... some that are recognized as having enduring social and artistic value and some that attract contemporary attention' (Australian Curriculum Assessment and Reporting Authority (ACARA) 2012). Texts for study include oral, print and multimodal forms, and students are 25 encouraged/required to 'interpret, appreciate, evaluate and create' literary texts in many forms and modes. Other features of the literary arm of this new Curriculum include the use of students' own choices of text for study, and the diversity of the range of texts identified as 'literary' across a range of media and forms. As Goodwyn (2012) notes, within these guidelines teachers have considerable auton30 omy in selecting texts to teach.

The decision to organise the Curriculum into these three areas, and the emphasis on 'Literature' as a discrete strand, grew out of considerable debate in the formative stages of the new Curriculum's development (National Currieulum Board 2009; Dixon 2012). An important priority for government in establishing the framework 35 and terms of reference for the new subject was that disciplinary experts from outside the field of education, most notably literary studies professors and experts in Australian literature, should be part of the discussion. Reflecting on the shaping and consultation phases of the development of the Australian Curriculum: English, where academics from both Education and Humanities/Arts faculties, together with

40 teachers from diverse localities and constituencies, discussed what the foci and parameters of a national English curriculum might be, Dixon $(2012,20)$ observed that there was no longer a direct match between English as a university discipline and English 'in all its diversity' as a subject at school. Considerable work was required to bridge the distance between the understandings, experience and expecta45 tions of all those involved in relation to what might be encompassed within the Literature strand, with respect to form, theory, content, pedagogy and priorities. The 'texts/literature' debate was a major focus of much discussion, with 'key fracture

\begin{tabular}{l} 
AQ2 lines' as Dixon (2012, 212) described them 'opening up between definitions of \\
\hline -literature" and "text" and "literary criticism" and "critical literacy"'.
\end{tabular}

50 The focus on 'Literature' within the Australian Curriculum: English, then, and the terminology that goes with it, is not a matter of serendipity or accident but a deliberate choice. There is an explicit emphasis on 'literature' and 'literary experience'; on literary texts as 'aesthetic', and 'the aesthetic nature of literary 
experience'. Texts to be taught include those of 'personal' as well as social and cultural value, as are digital and multimodal texts. Students are expected to write or make as well as read and/or analyse or 'appreciate' literature in diverse forms. The terms 'literary', 'aesthetic' and 'appreciation' collocate with words like 'create' (e.g. students create 'their own literary texts', language is used to create 'emotional, intellectual or philosophical effects', stylistic choices create 'multiple layers of interpretation and effect', and students (again) create 'imaginative writing in different forms and genres') and 'personal' (e.g. texts are of 'personal, social, cultural and aesthetic value', students identify 'personal ideas, experiences and opinions about literary texts' and use 'personal knowledge of literary texts') (ACARA 2012).

There's a provocative amalgam here of how 'the aesthetic' in this context might be viewed; a context in which canonical print literature ('Literature') continues to be important, but one in which multimodal texts are also to be 'interpreted, appreciated, evaluated and created' (ACARA 2012) in appropriate ways. What does aesthetic mean, in such a context? What kinds of texts and qualities of texts does it signal, what frames of reference and what kinds of reading/viewing and production practices does it activate, and what kinds of attention should be paid? For many Australian teachers and other commentators, moreover, what is striking about the language of the new Curriculum is the way in which the term 'aesthetic' is used more or less unproblematically, as is its cousin 'appreciation'. At one level, this usage glosses over decades of theoretical and epistemological difference and debate with respect to the category 'literature'; to do with unquestioned assumptions of consensus on what constitutes the aesthetic, and which texts might be regarded as such. At another, it opens a pathway to thinking about and describing texts and experience of a particular kind without importing the 'baggage' (Morgan 2007) sometimes associated with the term 'literature', when that term is read as referring exclusively to the heavyweight high-culture texts of the English tradition (Misson and Morgan 2006; Morgan 2007), and quite specific reading and responding practices (Eagleton 1985/6; Pattersen 2013).

The sets of ideas and associations marshalled by the words 'aesthetic' and (to a lesser extent, perhaps) 'appreciation' here, on the one hand, connote a set of traditional practices and subject formations, but, on the other, open up the invitation to work with a wide range of modes and text-types. The nomenclature asserts the value of a particular type of experience and perspective as central to English curriculum ('literary literacy') - at the core of what Green (2002) terms 'a literacy project of our own'. It also opens up the possibility of broadening the texts and modes that might be considered literary and aesthetic, and warrant 'literary' attention, in a view of English where multimodality is explicitly incorporated under the umbrella of literacy. What 'aesthetic' means within this context, what frameworks of analysis and creation to adopt, and how to develop close and careful 'literary' readings within 'English' are major challenges, not just for English curriculum within Australia but more generally.

What happens to classic and contemporary traditional forms of literary text if this 'Literature' dimension of the subject is maintained in a context where 'aesthetic' qualities are valued across a range of forms, and digital and multimodal texts can be deemed 'literary' and appropriate for study? Can the presence and strength of both be comfortably and coherently maintained?

While political agendas, as always, attend and circulate around the new Curriculum, particularly those concerned with assessment, international competitiveness and 
national identity, the foregrounding of literature and the aesthetic as represented in the Australian Curriculum: English document has been generally welcomed by the English and literacy teaching community. The opportunity is here for literature to be an active presence in curriculum - to be approached in ways that enhance and deepen pleasure and exploration; enhance children's understandings of texts and how they work; enhance understandings of the nature of reading, of oneself, and of the world; and develop critical analysis and critical literacy. It encourages the incorporation of 10 literature from a wide range of cultures, reflective of the diversity of students in contemporary Australian schools, globalisation, and rapidly transformed and hybridising iterations of cultural identity. Working with literary texts creates opportunities for imagination, production, creativity and play, and for exploring alternate structures, elements and conventions that organise and come to the fore in different modes.

15 Literacy constructed as 'design' provides one way of thinking of this broader canvas; phenomena characteristic of children's experience of text and story, including participatory culture and transmedia narratives, provide others.

This recognition of a wider and more diverse range of forms within the Literature strand allows for the study of literature (including but extending beyond

20 traditional classic print and oral forms) to encompass visual, multimodal and digital forms, and also extend beyond Anglophone cultural parameters. This view of literature is consistent with the recognition of the diverse and multiple ways in which contemporary meaning is made, and the need for students to be critical, capable and creative users of digital and multimodal forms of literacy, alongside traditional 25 print-based forms.

\section{Changing textual worlds}

Literature as traditionally defined is valued for its powerful use of language, the ways in which it represents the world, the deep engagement it invites, and the pleasures, insights and understandings it can prompt for reflective readers. These are

30 still central, but the range of elements to attend to has broadened to include other kinds of meaning-making, in the view of literacy characterised by the New London Group (1996), Kress (2003a), Gee (2003) and others as design. Curriculum is opened up to forms of aesthetic text that include but extend beyond so-called 'classic' texts in traditional forms. Children's textual worlds, and the kinds of 'literary' 35 texts they encounter, include but extend beyond traditional forms of literature and print literacy. As Unsworth $(2006,1)$ notes, 'the ways in which children and young people interact with literary texts are being profoundly influenced by the internet and the world wide web (www) as well as other aspects of contemporary Information and Communication Technologies)'. He cites Mackey's observation (Mackey $1994,17)$ that 'to talk about children's literature in the normal restricted sense of children's novels, poems and picture books, is to ignore the multi-media expertise of our children' (Unsworth 2006, 1).

Comments such as these point not only to the diversity and mix of forms that children's literature might take, but also to the active role of children as makers and creators - as expert in 'production' as well as 'reception', to use unduly exclusive terms. We are seeing changes in the patterns of children's reading, in children's experience of texts, and in their exposure to imaginative textual worlds. It is not that children's literature as traditionally understood has disappeared, but there are changes under way. As Hewings (2009, 330 1) deseribes, 
at the turn of the millennium children's literature is thriving despite the changes in lifestyle and leisure habits of many children, but equally its forms are changing and becoming more fluid under the combined pressures of new media, globalization, and changing concepts of the boundaries between childhoed and adultheod.

There is by now a well-established literature on the cross-platform nature of much contemporary narrative, transmedia navigation and story-telling (Jenkins et al. 2006;

AQ3 Berger and McDougall fortheoming), and also on the multimodal and participatory nature of young people's engagement with, and production of, texts of many kinds, particularly digital. Familiar too are arguments on the need for English and Literacy curriculum (or Language Arts and Reading) to include popular culture forms, and for the bringing together of insights and theoretical frames incorporating multimodal dimensions (e.g. Kress 2003a; Kress and Burn 2005; New Londen Group 1996), as well as from Media and New Media studies (e.g. Alvermann 2010; Davies and Merchant 2009; Willett, Robinsen, and Marsh 2009).

Adopting this broad view of literature and its integration across the curriculum for classroom practice raises questions about orientation, texts and pedagogy, in different ways for primary and junior secondary years, and also for senior English curriculum. It raises questions about the kinds and forms of texts to be approached as literature in the classroom, about frameworks for analysis and production, and about pedagogy as well as curriculum.

Traditional forms of literary texts, where language is used in creative and imaginative ways, clearly remain important. To argue for the inclusion of a broader range of texts alongside picture-books, novels, and other forms of traditional literature is not to deride the value of those forms. Rather, it is to recognise the diversity of children's experience of finely shaped imaginative worlds, and the ways in which new technologies and possibilities for meaning-making are creating new textual forms. Space is required for both, with the need to value and attend to both traditional and contemporary forms, and to the ways in which narratives morph across genres and modalities. There are new forms of narrative, new ways of telling stories, new ways of positioning readers, and new forms of participation and engagement, through a range of emergent, digitally enabled cultural sites and forms, that would seem to repay close study of what might be thought of as a 'literary' kind.

\section{Participatory culture: access and opportunity}

'Participatory culture' (Jenkins et al. 2006) provides a context in which young people expect to be actively involved in the textual, digital world, as both consumers and producers; readers/viewers/players and creators. Participatory culture, and transmodal experiences of narrative, raise challenges in determining the kinds of texts that might be deemed 'literary', and also what 'production' or 'creativity' might entail.

For children and young people at ease in the digital world, production can be a central part of reading and participation, with options for making and creating in relation to texts and narratives from both within and outside the digital world. Examples abound of observations of young children's out-of-school early play that crosses readily between online and offline worlds, in stark contrast, often, to the more formal parameters and restraints they meet in school (e.g. O'Mara and Laidlaw 2011; Marsh 2010). Similarly, there is a rich vein of studies illuminating 
high levels of skill, energy, creativity, representation, communication and satisfaction amongst young people using and creating digital texts for their own purposes out of school, with considerations of what might be learnt from these studies for more formal education contexts.

The capacity to copy, mash, change, spoof, and in other ways create and share new literary digital texts or paratexts is an important affordance of contemporary technologies and central to participatory culture. But at present, not all children have the access or capacity to contribute equally, should they wish to do so. While

10 it is clearly the case that large numbers of young people are taking up these opportunities (Jenkins et al. [2006, 3] cite Pew Internet studies for 2005 young people in North America that show 'more than one-half of all teens have created media content and roughly one third of teens who used the internet have shared content they produced'; and this in a period predating the massive growth of social 15 networking sites), it is important nonetheless to recognise that the degree to which activity such as this is taking place, where it is happening, and by whom, varies. In Australia, a much smaller proportion of young people are active in this way. Australian Bureau of Statistics figures for 2012 show that 'creating online content' was the most rapidly growing form of internet activity amongst young people aged $205-14$, with the number of children engaged in creating content rising since 2009 by $21 \%$ for children aged $5-8,14.5 \%$ for children aged $9-11$ and $5 \%$ for children aged 12-14 (Australian Bureau of Statistics (ABS) 2012). However, only 164,000 engaged in this activity, compared with the 1.47 million playing online games, 800,000 downloading videos, movies or music, or 700,000 visiting or using social 25 networking sites.

Figures such as these on young people's internet activities, however, fail to provide 'the full picture' of children's experience of narrative, or 'literary' texts in online worlds. In addition to watching videos, playing online games and using social network sites, the textual experiences of young people include participation 30 of a different kind - visiting fan fiction sites, making and creating paratexts for filmic, manga, TV and other narratives, creating new versions and scenarios, making and uploading spoof or tribute YouTube videos and so on. The (book) publishing industry already actively utilises cross-platform affordances to connect players/readers with their products. Book series such as Warrior Cats (Hunter 2003-13), for example, are designed from the outset to be integral with the online site, with character portraits, role play games, design your own avatar, skill lists, glossaries, clans, play tips, a manga app, 'extras' including videos and T-shirts, Warrior's quizzes and more. Many similar examples could be given.

Warrior Cats, and figures like those above, underline the importance of incorpo40 rating digital and transmedia experiences of text and story into English curriculum, recognising the pervasiveness of texts and experiences like these in students' lives. They underline the need also to help students explore, analyse and reflect on them, raising questions about how the 'literary' and 'aesthetic' qualities and experiences that literary English conceived multimodally entails might be understood and 45 brought to bear. They also underline the need to help all children acquire the operational skills and confidence to create digital texts of diverse kinds, so that not only those with access, skills and interests independently of school are able to do so. If the 'aesthetic' and 'personal' dimensions of engagement with text associated with 'literary' and 'creative' kinds of English are to be valued in relation to multimodal texts, there needs to be at least some capacity for the development of texts of this 
kind. This raises questions, in turn, about the kinds of technological skills and knowledge English teachers themselves have or should have. While the logic of developing a comprehensive model of Multiliteracies is that the nature, logic and affordances of different modes are mapped and recognised, and many teachers seek out opportunities to learn new forms and technologies, the production as well as 'appreciation' of multimodal aesthetic texts as a central part of English remains challenging.

\section{Multimodal aesthetic texts}

The senior secondary years of centrally set curriculum and examination provide a key testing ground for the acceptance of multimodal forms of text and literacy, and the inclusion of multimodal texts other than film within English in high-stakes examination contexts marks a significant move forward in institutional acceptance of multimodal conceptions of literature and literacy. While the study of Film within senior English is now relatively well established, other non-print forms are less familiar. Bearne (2009) makes the important point that not all multimodal texts are screen-based. One case in point is the Graphic Narrative, or Graphic Novel. In Victoria, in 2014, the range of texts on the centrally prescribed and examined list for the Victorian Certificate of Education Year 12 English and English as an Additional Language courses will expand to include Graphic Novels, or Graphic Narratives, with the setting of Spiegelman's (2003), The Complete Maus, and the replacement of the Film Text category with Multimodal Texts. By virtue of its inclusion on the text list, The Complete Maus is deemed to meet the Victorian Curriculum and Assessment Authority's (VCAA) (2013, 1-2) criteria for 'literary merit' ascribed to all texts named, which includes being deemed 'worthy of close study' and 'an excellent example of form and genre'.

In graphic novels and narratives ('Comics' as the singular noun; Chute 2008), word and image work together, but their integration entails something other than the parallel existence of these two logics separately. Space and time are central. The key generic features of comics, as McCloud (1993) argues, are panels and the gutters between them, with time a third crucial element. The combinations and layering of image and words within and between panels use space and relationships to create a sense of sequencing and time. No-other medium, according to-Crutcher

AQ4 $_{\curlywedge} \quad(2011,55 \quad 56)$,

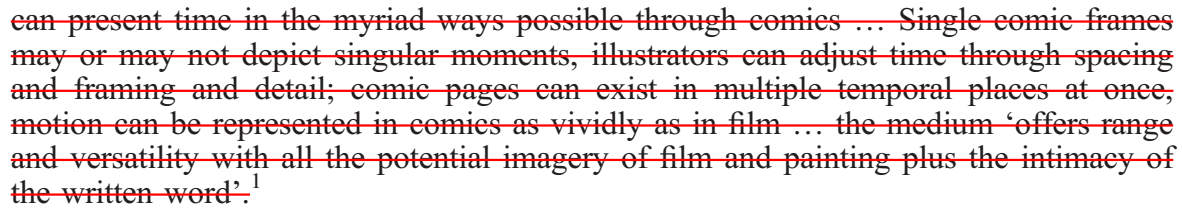

The decision to add The Complete Maus to the text list at this level, the shift of category from 'Film' to 'Multimodal Texts', and the acceptance of this move by Victorian teachers and the educational community, attest to the growing recognition of the diversity of literacies and modalities, with attendant 'logics' and contemporary communicative forms. The inclusion of Maus as a text set for study is one of a number of signs of increased acceptance of multimodal texts. It reflects recognition of the need for versions of the subject-area that maintain its traditional focus and 
identity, but newly cast, as Kress (2002), Green (2002), Missen (2012) and others argue for, with literary, imaginative, creative, ethical and aesthetic foci part of its textual world.

While graphic narratives expand the boundaries of what is understood by 'texts' and 'aesthetic texts', and how to work with them, it is perhaps with videogames that the 'threats and challenges' as well as possibilities of extending literary/aesthetic text categories within English currently appear most vividly. Working with students playing, analysing and creating videogames in secondary classrooms in

$10 \quad$ Australia $^{2}$ has made subject boundaries and expectations highly visible and raised questions about how to conceive of games in literary/literacy terms when existing constructions even of multimodal literacy seemed inadequate to encompassing what was entailed. Classroom pedagogy and curriculum brought subject boundaries close to breaking point, particularly for English and for literacy (Beavis and O'Mara 15 2010). The study foregrounded the need for a model for working with videogames that was sensitive to the active and embedded nature of games, and conceived of them as both text and action (Apperley and Beavis 2013; Beavis, O'Mara, and MeNeice 2012; Bradford 2010; Walsh 2010).

Aarseth's (1997) stern warning that bringing frameworks drawn from Literary 20 theory and print literature to bear on videogames dangerously distorts and misunderstands the nature of games remains highly pertinent, and highly challenging in the context of the argument advanced here, that literature as a category can manage media shift. Yet this need not necessarily be the case. As Bradford (2010) argues, 'while discussions of games have often hinged on definitions: for instance, whether they are best understood in relation to ludology (the study of games, their forms and categories) or to narratololgy (how narratives work)', they may be more usefully understood as 'hybrid products which incorporate narrative and game elements while engaging players in energetic action and (in many cases) interpersonal and social processes'. She argues for the incorporation of a range of perspectives and frameworks for analysis: 'As complex, evolving forms, they invite analytic strategies which take account of the multifarious ways in which they produce meaning and create subject positions for players' (Bradford 2010, 54).

The study of LA Noir as 'authorless text' in English Literature, by A Level English students together with university undergraduates in the United Kingdom (Berger and McDougall, fortheoming), provides an example of how games understood as text might be incorporated into English as instances of literary/aesthetic text that crosses media forms. Students studied the game within 'the orthodox framing of the English literature curriculum' (Berger and MeDougall, fortheoming) but took into account also Game Studies perspectives and parameters. Students wrote 40 blogs about their experience of the game, using the "language game" of English Literature, culminating in answering a question constructed within the idioms of the subject's set text "final examination"” (Berger and MeDougall, fortheoming). They switched frames to teach their teachers to play the videogame, then reverted to their role as English (Literature) students to work through study guide materials 45 'designed to reproduce the conventions of the "study guide" for literature education' (Berger and MeDougall, fortheoming).

From a different starting point, still working with videogames, Australian teacher Jennifer Russell invited Year 10 students to bring in instances of multimodal aesthetic texts in response to traditional and multimodal forms of literature, as a 50 means to demonstrate and extend their understanding of literature (Russell and 
Beavis 2012). As part of a sequence of lessons on traditional literary literature, she invited her Year 10 students to use any text of their own choice to illustrate their understanding of literary devices as traditionally defined. When one student, Erin, asked to write on the videogame Assassin's Creed II, to illustrate points of literary analysis, Jennifer was prepared to accept this as an option, once Erin had convinced her that the game would allow her to do so at an appropriate level of depth and complexity. In a later task, for her 'creative response' to Tracey Moffatt's black and white photographic series Laudanum (1999), Erin created a four-person narrative using the game Runescape, employing a complicated and ingenious set of technical strategies to do so.

In response to Lurhman's film Romeo and Juliet, she built a Minecraft representation, including rooms for each character, with symbolic contents and furnishings. The chapel where the lovers die provided a metaphoric overview of the narrative. The chapel was divided into two sides, each created to symbolise aspects of the Montague and Capulet families. Moving down the chapel, the seasons changed from Spring and Summer to Winter, reflective of the lovers' changing fortunes, while a stream of water - 'the stream of life' - ran down the centre aisle. A series of signposts reference significant scenes and moments in the text, as the player/viewer progresses towards the altar, where the film reaches its climax and denouement (Figure 1).

The use of Minecraft, a game essentially organised around building rather than narrative, required an imaginative and metaphoric leap and translation of the film, into spatial and symbolic terms. The shift here is not just one of narratives crossing platforms, although it is that too. What made all three examples 'work' as highlevel responses within this literary English class was Erin's detailed and specific knowledge of these individual games, her similar close reading of the 'set texts', her understanding of the generic requirements to demonstrate knowledge of literary elements and devices, the imaginative vision required, and the skill and creativity entailed in both the making and analysis of these games.

While this diversity of texts is increasingly welcomed into English and Literary curriculum, and these texts feel part of a familiar literary family, questions remain

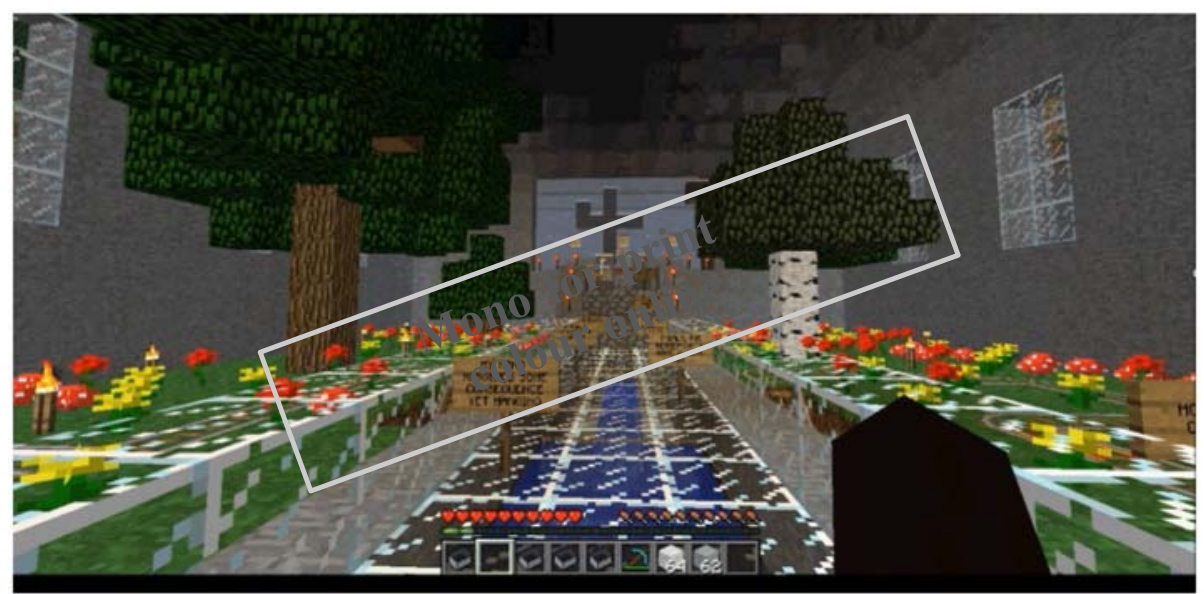

Figure 1. Romeo and Juliet, Minecraft. 
about the appropriateness of bringing literary frames of reference from literacy, however broadly defined, to bear on the analysis of other than formally 'literary' texts in traditional form. As Berger and McDougall (fortheoming) found, working with videogames as 'authorless texts' 'raises epistemological questions about "subject identity", and the implications for digital transformations of texts or ideas about cultural value in schooled literacy and also the politics of "expertise" in pedagogic relations'. Working this close to the boundary between dramatically different genres highlights as yet unanswerable questions about frames of reference for analysis for exploring 10 transmedia literary/aesthetic texts within English; about how to work within the parameters and analytic frameworks that respect and recognise the affordances of these forms (Aarseth1997; Buckingham and Burn 2007; Frasea 2003).

The effort of the Multiliteracies movement is to provide a comprehensive account of the multiple ways in which meaning is made in digital times, and to

15 support students in their use, analysis, creation and enjoyment of texts and literacies of many kinds. The impulse to embrace the richness and diversity of digital and transmedia culture and children's textual worlds, and to bring the understanding of those texts and the forms of participation they foster into the classroom, is advocated and enacted by teachers and scholars alike - new media/new literacy and 20 children's literature researchers, professional associations, children's media bodies and more. To do so envisages an English curriculum where aesthetic texts in multiple forms are part of children's narrative, viewing and reading worlds, where pleasure, the personal, the aesthetic and the creative are central elements of textual experiences in and out of school. In and amongst such diversity, however, we must take care not to lose or undervalue literature in its familiar form, and the affordances of print literature. As Kress (2003b, 152) usefully observes, imagination and the direction of attention differ across written texts and those organised on principles of design:

Imagination produced by engagement with the written text was both an acceptance of 30 externally given order and the possibility of action seen as a move towards an inner world. Imagination in the sense required by the demands of design - my imposition of order on the representational world, whether as text maker or as reader - is a move toward action in and on the outer world. One was a move to contemplation; the other is a move toward involvement in outward action.

35 Questions confronting English and the literary or aesthetic include how to balance print and non-print text in the world of transmedia narratives; what frameworks for analysis are appropriate for diverse forms and whether there are common elements to value here; and how to envisage the relationship between literature in the multimodal age and the 'deep purposes' of English as 'the subject that provides means for understanding the relation of an inner world of imagination and desire with an outer world of culture and social demands (Kress 2002, 17). While directions and priorities are emerging, challenges still remain. For literature to continue as a valued and viable category in English in contemporary times, we clearly need to continue to engage difficult questions such as these.

\section{Notes}

1. A more extended version of this discussion was prepared for the VCAA (http://www. vcaa.vic.edu.au/Pages/vce/studies/english/index.aspx\#H2N100C7). 
2. Beavis, C., Bradford, C., O'Mara, J., and Walsh, C., Literacy in the Digital World of the Twenty First Century: Learning from Computer Games. Australian Research Council 2007-2009. Industry partners: The Australian Centre for the Moving Image, The Victorian Association for the Teaching of English, The Department of Education and Early Childhood Development, Victoria (Research Fellow: Thomas Apperley; additional research assistance: Amanda Gutierrez).

\section{Note on contributor}

Catherine Beavis is a Professor of Education at Griffith University. She teaches and researches in English and Literacy Education, young people and digital culture, with a particular focus on videogames as new narrative and communicative forms, and the implications of young people's engagement with digital culture and videogames for education. Recent publications include Literacy in 3D: An Integrated Perspective in Theory and Practice (ACER, 2012), co-edited with Bill Green, and Digital Games: Literacy in Action (Wakefield Press/AATE, 2012), co-edited with Jo-Anne O’Mara and Lisa McNeice.

\section{References}

Aarseth, Espen. 1997. Cybertext: Perspectives in Ergodic Literature. Baltimore, MD: Johns Hopkins University Press.

Alvermann, Donna. 2010. Adolescents' Online Literacies: Connecting Classrooms, Digital Media and Popular Culture. New York: Peter Lang.

Apperley, Thomas, and Catherine Beavis. 2013. "A Model for Critical Games Literacy." E-Learning and Digital Media 10 (1): 1-12.

Australian Bureau of Statistics (ABS). 2012. "Children's Participation in Cultural and Leisure Activities, Australia, April 2012.” http://www.abs.gov.au/ausstats/abs@.nsf/mf/ 4901.0 Accessed 24 March 2013.

Australian Curriculum Assessment and Reporting Authority (ACARA). 2012. Australian Curriculum: English 5 /Literature. Accessed 27 May 2013. http://www.australiancurriculum.edu.au/English/Literature.

Bearne, Eve. 2009. "Multimodality, Literacy and Texts: Developing a Discourse." Journal of Early Childhood Literacy 9 (2): 156-187. doi: 10.1177/1468798409105585.

Beavis, Catherine, and Joanne O'Mara. 2010. "Computer Games: Pushing at the Boundaries of Literacy." Australian Journal of Language and Literacy 33 (1): 65-76.

Beavis, Catherine, Joanne-O'Mara, and Lisa MeNeice, eds. 2012. Digital Games: Literacy into-Action. Adelaide: Wakefield Press.

Berger, Richard, and Julian McDougall. Reoding Videogames as (Authorless) Literature. Literacy 47 (3). doi:10.1111/lit.12004.

Bradford, Clare. 2010. "Looking for My Corpse: Video Games and Player Positioning." Australian Journal of Language and Literacy 33 (1): 54-64.

Buckingham, David, and Andrew Burn. 2007. "Game Literacy in Theory and Practice." Journal of Educational Media and Hypermedia 16 (3): 323-349.

Chute, Hillary. 2008. "Comics as Literature: Reading Graphic Narrative." The Changing Profession. PMLA 123 (2): 452-465.

Davies, Julia, and Guy Merchant. 2009. Web 2.0 for Schools: Social Participation and Learning. New York, NY: Peter Lang.

Dixon, Robert. 2012. 'English' in the Australian Curriculum: English. English in Australia, 47(1): 19-26.

Eagleton, Terry. 1985/6. "The Subject of Literature." Cultural Critique, 2: 95-104.

Frasea, Gonzalo. 2003. "Ludologists Love Stories Toø: Notes From a Debate that Never Fook Place." Accessed 9th May 2013. http://www.ludology.org/articles/frasea_leveHp2003.pdf.

Gee, James Paul. 2003. What Video Games Have to Teach Us about Learning and Literacy. New York: Palgrave. 
Goodwyn, Andrew. 2012. "The Status of Literature: English Teaching and the Condition of Literature Teaching in Schools." English in Education 46 (3): 212-227.

Green, Bill. 2002. “A Literacy Project of Our Own.” English in Australia 134: 25-32.

Hewings, Anne. 2009. “Contemperary Transformations: Introduction." In Children's Literature: Approaches and Territories, edited by Janet Maybin and Nicola J. Watson, 329 333. Basingsteke: Palgrave MeMillan.

Hunter, E. 2003-2013 Warrior Cats. HarperCollins www.warriorcats.com. Accessed 27 May 2013.

Jenkins, Henry, Katie Clinton, Ravi Purushotma, Alice J. Robison, and Margaret Weigel. 2006. Confronting the Challenges of Participatory Culture: Media Education for the

1521 st Century. Cambridge: MIT Press.

Kress, Gunther. 2002. "English for an Era of Instability: Aesthetics, Ethics, Creativity and Design." English in Australia 134: 15-24.

Kress, Gunther. 2003a. Literacy in the New Media Age. New York: Routledge.

Kress, Gunther. 2003b. "Interpretation or Design? From the World told to the World Seen"

20 In Art, Narrative and Childhood, edited by Morag Styles and Eve Bearne, 137-153. Stoke on Trent: Trentham Books.

Kress, Gunther, and Andrew Burn. 2005. "Pictures from a Rocket: English and the Semiotic Take." English Teaching: Practice and Critique, 4 (1): 95-105 http://education.waikato. ac.nz/research/files/etpc/2004v4n1art7.pdf.

25Q5 Mackey, Margaret. 1994. "The New Basics: Learning to Read in a Multi-Media World." English in Education 28 (1): 9-19.

AQ6 Marsh, Jackie. 2010. "Young Children's Play in Virtual Online Worlds." Journal of Early Childhood Research 8 (1): 23-39.

McCloud, S. 1993. Understanding Comics: The Invisible Art. New York: Harper Collins/ Kitchen Sink Press.

Misson, Ray. 2012. "Understanding about Water in Liquid Modernity: Critical Imperatives for English Teaching." English in Australia 47 (1): 2735.

Misson, Ray, and Wendy Morgan. 2006. Critical Literacy and the Aesthetic: Transforming the English Classroom. Illinois: National Council of Teachers of English.

35 Morgan, Wendy. 2007. "The Literary Work, or the Work We Do with Literary Texts?" English in Australia 42 (2): 34-38.

National Curriculum Board. 2009. Shape of the Australian Curriculum: English http://www. acara.edu.au/verve/_resources/Australian_Curriculum__English.pdf Accessed 25 May 2013.

40 New London Group. 1996. “A Pedagogy of Multiliteracies: Designing Social Futures.” Harvard Educational Review, 66 (1). Accessed 9th May 2013. http://wwwstatic.kern.org/ filer/blogWrite44ManilaWebsite/paul/articles/A_Pedagogy_of_Multiliteracies_Designing_ Social_Futures.htm.

O'Mara, Joanne, and Linda Laidlaw. 2011. "Living in the iworld: Two literacy Researchers Reflect on the Changing Texts and Literacy Practices of Childhood." English Teaching: Practice and Critique 10-(4): 149 159. Accessed 9th May 2013. http:/leducation.waikato.ae.nz/research/files/etpe/files/2011v10n4nar2.pdf.

Patterson, Annette. 2013. "The Legacy of Ian Hunter's Work on Literature Education and the History of Reading Practices: Some Preliminary Remarks." History of European Ideas. doi:10.1080/01916599.2013.784038.

Russell, Jennifer, and Catherine Beavis. 2012. "Dickens, Sucker Punch, Moffatt, Avatars and Forensic Evidence." English in Australia 47 (2): 27-35.

Spiegelman, Art. 2003. The Complete Maus: A Survivor's Tale. New York: Voyager.

AQ7 Unsworth, Len. 2006. E-Literature for Children. New York: Routledge.
55 Nictorian Curriculum and Assessment Authority (VCAA). 2013. "2014 VCE English/EAL Text List." Accessed 9th May 2013. http://www.vcaa.vic.edu.au/Documents/notices/2013/ notice27-2013-2014VCEEnglishEALTextList.pdf.

Willett, Rebecea, Muriel Robinson, and Jackie Marsh, eds. 2009. Play, Creativity and Digital Cultures. New York: Routledge.

60 Walsh, Christopher. 2010. "Systems-Based Literacy Practices: Digital Games Research, Game Play and Design." Australian Journal of Language and Literacy 33 (1): 2440. 